\title{
MERCADO E IGUALDADE: NOTAS SOBRE O USO DO TERMO "MERCADO" E UMA CRÍTICA A DWORKIN
}

\section{MARKETS AND EQUALITY: REMARKS ON THE USE OF THE TERM 'MARKETS' AND A CRITIQUE OF DWORKIN'S EQUALITY OF RESOURCES}

\begin{abstract}
LEANDRO MARTINS ZANITELLI
Doutor em Direito pela Universidade Federal do Rio Grande do Sul (UFRGS). Professor Adjunto na Faculdade de Direito e Ciências do Estado da Universidade Federal de Minas Gerais (UFMG). Belo Horizonte, Minas Gerais, Brasil. leandrozanitelli@gmail.com
\end{abstract}

\begin{abstract}
RESUMO
0 artigo tem dois objetivos. Primeiro, procura discernir os sentidos com os quais o termo "mercado" é usado na literatura, ora como falta de impedimentos jurídicos à liberdade de contratar, ora como relações suscetíveis a variações de oferta e demanda, ora como falta de coordenação e ora, finalmente, como "lugar" de satisfação de preferências. O segundo objetivo é ilustrar como o descuido com essa variação de significados atrapalha argumentos normativos sobre o mercado. Trata-se, para tanto, do argumento de Dworkin sobre a imprescindibilidade do mercado para a igualdade de recursos. Afirma-se que esse argumento é problemático porque, embora dependa de o mercado ser tido como "lugar” para a satisfação de preferências, presume, em geral, que isso seja assegurado simplesmente pela falta de impedimentos jurídicos à liberdade de contratar.
\end{abstract}

Palavras-chave: Dworkin; igualitarismo; mercado.

\begin{abstract}
The article has two goals. Firstly, it tries to discern the meanings in which the word "market" is employed, sometimes as the lack of legal impediments to the freedom of contract, sometimes as relationships susceptible to supply and demand variations, sometimes as lack of coordination and sometimes, finally, as a "place" to the fulfillment of preferences. The second goal is to show how a disregard of these several meanings may truncate normative arguments about markets. To this end, the paper assesses Dworkin's argument on the inescapability of markets for attaining equality of resources. It is argued that this argument is problematic in that, although drawing on the market being understood as a "place" for preferences satisfaction, it assumes, in a general way, that such desideratum could be achieved simply through the abolition of legal constraints to transactional freedom.
\end{abstract}

Keywords: Dworkin; egalitarianism; markets. 


\section{SUMÁRIO}

INTRODUÇÃO; 1 MERCADO E NÃO MERCADO; 1.1 Mercado como liberdade (formal) de contratar; 1.2 Mercado como liberdade para alienação onerosa; 1.3 Mercado como não contrato; 1.4 Mercado como não coordenação; 1.5 Mercado como "lugar" de satisfação de preferências; 1.6 Relações entre os diferentes sentidos da dicotomia; 2 VÁRIOS "MERCADOS": ALGUM PROBLEMA?; 2.1 A igualdade de recursos de Dworkin e o mercado; 2.2 Qual mercado? O problema da preferência pelo comércio razoável; CONCLUSÃO; REFERÊNCIAS.

\section{INTRODUÇÃO}

Possivelmente porque a ideia de "mercado" nos é familiar, frequentemente nos envolvemos em discussões sobre a defensabilidade moral do mercado ou a bondade (ou maldade) das suas consequências sem nos preocuparmos em definir com precisão do que estamos falando. 0 termo “mercado" tem, no entanto, nuanças de significado, acentuadas por certos desenvolvimentos da ciência econômica nas últimas décadas, como o da "economia dos custos de transação", de Williamson ${ }^{1}$ e o das "variedades de capitalismo", de Hall e Soskice, ${ }^{2}$ entre outros. Esses autores dissociam as noções de "capitalismo" e "mercado" ao tratarem o mercado como uma entre várias soluções institucionais possíveis (no caso de Williamson, ao lado dos contratos e da hierarquia) ou ressaltarem a importância, maior em alguns países do que em outros, de "interações estratégicas" que se contrapõem ao mercado e permitem aos agentes auferir certas vantagens da coordenação (como no caso das variedades de capitalismo de Hall e Soskice). ${ }^{3}$

Este trabalho tem dois objetivos. O primeiro é fazer um esforço analítico para diferenciar certos sentidos atribuídos à palavra "mercado", objetivo de que se ocupará a primeira seção. 0 segundo é sugerir que argumentos sobre o valor moral do mercado ou suas consequências empíricas podem falhar devido à confusão entre dois ou mais desses sentidos. A título de ilustração, a segunda seção examina, então, o argumento sui generis de Dworkin em favor do mercado como condição para a igualdade. Procura-se demonstrar que esse argumento ignora o risco de os agentes se comportarem de uma maneira que solapa a igualdade que o

\footnotetext{
${ }^{1}$ WILLIAMSON, O. E. The mechanisms of governance. Nova York: Oxford University Press, 1996.

${ }^{2}$ HALL, P. A.; SOSKICE, D. An introduction to varieties of capitalism. In: HALL, P. A.; SOSKICE, D (coord.). Varieties of capitalism: the institutional foundations of comparative advantage. Nova York: Oxford University Press, 2001.

${ }^{3}$ A ideia de que o mercado seja uma característica exclusiva do capitalismo também é contestada por autores simpáticos ao socialismo de mercado, como MILLER, D. Market, state and community: theoretical foundations of market socialism. Oxford: Clarendon Press, 1989.
} 
mercado seria supostamente capaz de atingir, um descuido que é possivelmente resultado de uma confusão entre duas acepções do termo "mercado".

\section{MERCADO E NÃO MERCADO}

Nesta seção, apresentam-se vários significados do termo "mercado". Quando se passa de uma acepção a outra, muda não apenas o que "mercado" quer dizer, mas também o que se considera como sua alternativa, o "não mercado". A seção tratará, portanto, de vários sentidos nos quais a dicotomia "mercado/não mercado" é entendida.

\subsection{Mercado como liberdade (formal) de contratar}

Em um sentido, há mercado se as pessoas são formalmente livres para contratar. “Formalmente" significa que se tem em vista, no caso, a falta de um impedimento jurídico à contratação.

Um problema da definição recém apresentada se refere à noção de "impedimento". Tradicionalmente, normas de direito contratual são classificadas como cogentes ou dispositivas. Diferentemente das cogentes, as normas dispositivas podem ter a sua aplicação ilidida pelas partes. Seria tentador, pois, afirmar que somente as normas cogentes constituem um impedimento à contratação, e que, em consequência, normas dispositivas e cogentes definiriam, respectivamente, o âmbito do mercado e do não mercado. 0 problema é que até mesmo as normas dispositivas terão de ser obedecidas a não ser que as partes satisfaçam aos requisitos para afastá-las. Esses requisitos são instituídos pelo que Ayres ${ }^{4}$ chama de normas de alteração. Em alguns casos, a norma de alteração pode requerer apenas que as partes entrem em acordo sobre uma cláusula diversa. Em outros, todavia, os requisitos para afastar uma norma dispositiva podem ser mais difíceis de atender. Por exemplo, em relação à norma dispositiva do art. 35 da Lei $n^{\circ} 8.245 / 1991$, que atribui ao inquilino certos direitos sobre benfeitorias necessárias e úteis, afirma-se que a alteração tem como requisito o de o contrato de locação não ser de adesão (enunciado $n^{\circ} 433$ das Jornadas de Direito Civil do Conselho da Justiça Federal). As partes seriam livres, portanto, para instituir um regime de benfeitorias alternativo ao do citado art. 35, desde que o contrato não seja de adesão. Em tal caso, seria ainda correto dizer que os contratantes

\footnotetext{
${ }^{4}$ AYRES, I. Regulating opt-out: an economic analysis of altering rules. Yale Law Journal, $\mathrm{n}^{\circ} .121,2012$.
} 
não estão sujeitos a nenhum impedimento, de modo que a lei vigorante é a do mercado, e não a do não mercado?

Outra questão sobre o conceito de impedimento se refere a casos nos quais, embora o contrato seja juridicamente válido, o direito contratual recusa às partes os meios para execução forçada da obrigação. É o que acontece nas chamadas “obrigações naturais”, de que são exemplo, no Brasil, as dívidas de jogo e aposta (Código Civil, art. 814). Há, em tal hipótese, um impedimento (e, portanto, uma limitação à liberdade), ou devem ser considerados como casos de impedimento apenas aqueles nos quais o direito negue validade ao contrato?

As dificuldades recém expostas mostram que a distinção entre mercado e não mercado baseada em limites à liberdade formal de contratar não é uma distinção de “tudo ou nada". Não se deve concluir, contudo, que ela seja ininteligível. Normas dispositivas são diferentes de normas cogentes, ainda que a diferença se torne menos nítida à medida que aumente a dificuldade para afastar as primeiras. Também não é um empecilho à distinção o fato de haver casos fronteiriços, como os das obrigações naturais, em que o impedimento à contratação, caso haja, não consiste na invalidade do contrato.

Ainda assim, pode-se ter dúvida quanto à pertinência de definir os limites do mercado $\mathrm{e}$ do não mercado com base em impedimentos jurídicos. A ênfase sobre tais impedimentos dá a impressão de que, à falta deles, será igualmente fácil para as partes contratar de uma maneira ou de outra. Há vários argumentos, contudo, para concluir que essa impressão é falsa e que, uma vez instituída a norma dispositiva $n$, pode ser difícil para as partes afastá-la em favor de $n^{*}$, mesmo que o único requisito jurídico para tanto seja a vontade das partes. ${ }^{5}$

A dificuldade para afastar a norma dispositiva (não obstante a falta de maiores entraves jurídicos) não se restringe aos custos (custos de transação) em que as partes precisam incorrer para chegar a um acordo, embora tais custos existam. A resiliência das normas dispositivas

\footnotetext{
${ }^{5}$ Essa é uma razão, dentre outras, para discordar de Tomasi (2012) quanto ao caráter fundamental e, consequentemente, merecedor de proteção constitucional das liberdades econômicas. Ao argumentar sobre a importância dessas liberdades para a autonomia ou "auto-definição" (self-authorship), o autor parece ignorar que a garantia jurídica de certas liberdades não impede que as pessoas sejam cerceadas em suas escolhas e, em consequência, não explica por que deveríamos nos preocupar tanto com os casos em que esse cerceamento provém de normas jurídicas.
} 
também é atribuída a uma preferência pelo status quo, ${ }^{6}$ a normas sociais ${ }^{7}$ e a problemas de informação assimétrica. ${ }^{8}$

Há uma tendência a tratar relações não sujeitas a normas cogentes como relações de mercado, e, consequentemente, a ineficiência que pode decorrer da resiliência de normas dispositivas como falha de mercado. É importante constatar, não obstante, que os efeitos de normas "a favor" (dispositivas) e "contrárias" (cogentes) à liberdade formal de contratar podem não ser tão diferentes quanto à primeira vista parecem.

\subsection{Mercado como liberdade para alienação onerosa}

Outro sentido é aquele no qual o mercado é relacionado à liberdade formal (isto é, à falta de impedimento jurídico) para alienar certos bens gratuita (simplificadamente, “liberdade para doar”) e onerosamente (“liberdade para vender”). Enquanto os bens sujeitos ao mercado seriam os que se podem doar e vender, bens não sujeitos ao mercado, em contrapartida, podem ser doados, mas não vendidos. ${ }^{9}$

O impedimento à venda, mas não à doação, é, por certo, um limite à liberdade de contratar, a exemplo dos demais limites instituídos por normas cogentes. Certos argumentos sobre o mercado, todavia, caracterizam-se justamente pela objeção à venda (por exemplo, de sangue, órgãos ou direitos parentais) daquilo que se admite que seja doado. ${ }^{10}$ Também se atribui, portanto, à dicotomia mercado/não mercado esse sentido mais restrito.

\subsection{Mercado como não contrato}

\footnotetext{
${ }^{6}$ KOROBKIN, R. The status quo bias and contract default rules. Cornell Law Review, n 83, 1998.

7 BERNSTEIN, L. Social norms and default rules analysis. Southern California Interdisciplinary Law Journal, $\mathrm{n}^{\circ}$ 3, 1993.

8 JOHNSTON, J. S. Strategic bargaining and the economic theory of contract default rules. Yale Law Journal, $n^{\circ}$ 100, 1990; SPIER, K. E. Incomplete contracts and signalling. RAND Journal of Economics, $n^{\circ}$ 23, 1992; BEN-SHAHAR, O.; POTTOW, J. A. E. On the stickiness of default rules. Florida State University Law Review, $n^{\circ} 33,2006$. Ressalve-se que a resiliência à que alude a literatura citada nem sempre é de normas legais dispositivas. In: BERNSTEIN, L. Social norms and default rules analysis. Southern California Interdisciplinary Law Journal, $\mathrm{n}^{\circ} 3,1993$, por exemplo, tem em vista práticas comerciais nas quais as cláusulas default são cláusulas costumeiras cujo conteúdo pode divergir do que é legalmente previsto.

9 Restam, evidentemente, duas outras possibilidades, a dos bens que se podem vender, mas não doar, e a dos que não se podem vender e doar.

${ }^{10}$ E.g., SATZ, D. Why some things should not be for sale: the moral limits of markets. Oxford: Oxford University Press, 2010.
} 
Juridicamente falando, tanto são contratos os que instituem obrigações que se cumprem imediata ou quase imediatamente (como uma compra à vista) como aqueles nos quais o cumprimento das obrigações é diferido ou que se caracterizam por prestações sucessivas (como contratos de fornecimento ou prestações de serviço continuadas). Há um sentido econômico, no entanto, no qual mercado e contrato são noções antitéticas. 0 que se considera como relações de mercado, em tal caso, são relações cujo preço responde a variações de oferta e demanda. À medida que sejam um anteparo a essas variações, os contratos de execução diferida e continuada constituiriam, portanto, uma força antimercado. Essa contraposição entre mercado e contrato é encontrada na "economia dos custos de transação", ${ }^{11}$ na qual contratos são considerados "mecanismos de governança" para a redução de custos, entre eles custos de comportamentos oportunistas. ${ }^{12}$

Tome-se, para exemplificar, uma relação entre dois agentes, $\mathrm{X}$ e $\mathrm{Y}$. X compra hoje de $Y$ uma quantidade $q$ da mercadoria $m$ a um preço $p$ por unidade. Se a relação entre $X$ e $Y$ é de mercado, $p$ está permanentemente sujeito a variações de oferta e demanda, de modo que, caso repitam a operação amanhã, a mesma mercadoria será vendida a um preço $p^{*}$ (em que $p^{*}>p$, $\mathrm{p}^{*}<\mathrm{p}$ ou $\mathrm{p}^{*}=\mathrm{p}$, a depender da oferta e da demanda). Imagine, em contrapartida, que $X$ e $Y$ tenham um contrato duradouro pelo qual $Y$ está obrigado a fornecer a $X$ uma quantidade $q$ de $m$ a um preço $p$ por um ano. Esse contrato faz com que $p$ permaneça imune a variações de oferta $e$ demanda pelo prazo estipulado, o que caracterizaria a relação entre $X$ e $Y$ como de não mercado.

No sentido recém mencionado, a distinção entre mercado e não mercado é, mais do que nunca, nuançada. A medida com que o contrato protege a relação entre $X$ e $Y$ contra variações de oferta e demanda é uma função das hipóteses nas quais o contrato entre $X$ e $Y$ pode ser unilateralmente desfeito e da eventual penalidade a arcar em caso de desfazimento. Por exemplo, o contrato pode determinar que $Y$ preste a $X$ a um preço $p$ salvo na hipótese em que um terceiro esteja disposto a adquirir a mesma mercadoria de $Y$ a um preço $p+n$. Esse contrato preservaria a relação entre $X$ e $Y$ contra variações de demanda, mas só até o limite em que uma variação faça elevar o preço a $p+n$ ou mais.

\footnotetext{
${ }^{11}$ WILLIAMSON, O. E. The mechanisms of governance. Nova York: Oxford University Press, 1996.

12 Outro mecanismo de governança é a hierarquia ou integração vertical, isto é, a integração à firma de uma atividade em substituição ao mercado (o "fazer em lugar de comprar"). V. KLEIN, B.; CRAWFORD, R. G.; ARMEN, A. A. Vertical integration, appropriable rents, and the competitive contracting process. Journal of Law and Economics, $n^{\circ} 21,1978$.
} 
Os limites entre o mercado e o contrato (como não mercado) variam, portanto, de acordo com o conteúdo do contrato e, consequentemente, também devido às normas jurídicas aplicáveis a esse conteúdo. Embora o Código Civil não seja claro a respeito, é comum entender que o direito brasileiro não admite contratos eternos. As partes são induzidas, pois, a instituir obrigações finitas ou contratar por um prazo, sob pena de o contrato ficar sujeito a resilição unilateral (com a única ressalva do art. 473, parágrafo único, do Código Civil). Ainda há, a esse respeito, o limite do art. 598 do Código Civil (nulidade da cláusula de prazo superior a quatro anos nos contratos de prestação de serviço). Outras normas, como as dos artigos 317 e 478, dão a uma das partes o direito a revisar ou resolver o contrato sob circunstâncias imprevistas.

Uma vez que o mercado seja contraposto ao contrato como anteparo a variações de oferta e demanda, é difícil justificar que não se faça também a contraposição do mercado a outras forças que, embora não caracterizáveis como contratos, conduzem a um resultado análogo. Uma delas é a preferência por equidade (fairness). ${ }^{13}$ Por exemplo, um agente pode se abster de aumentar preços em circunstâncias nas quais tal aumento não seja considerado equânime, seja pelo próprio agente ou por outros (como consumidores). Outra são os custos de transação: como mudar de parceiro acarreta custos, os agentes podem ignorar variações de oferta e demanda a fim de não incorrerem nesses custos. ${ }^{14}$ Relações duradouras não baseadas em contrato podem ser mantidas, por fim, com a expectativa de que a interação repetida evite condutas oportunistas. ${ }^{15}$

\subsection{Mercado como não coordenação}

Em outra acepção, o mercado é caracterizado pela falta de coordenação entre os agentes. Essa contraposição é característica da literatura sobre as chamadas "variedades de capitalismo", ${ }^{16}$ na qual se costumam distinguir uma variedade de capitalismo liberal (exemplificada por países como EUA e Reino Unido) e uma variedade coordenada (Alemanha e

13 KAHNEMAN, D.; KNETSCH, J. L.; THALER, R. (1986). Fairness as a constraint on profit seeking: entitlements in the market. American Economic Review, $\mathrm{n}^{\circ} 76,1986$; RABIN, M. Incorporating fairness into game theory and economics. American Economic Review, nº 83, 1993.

${ }_{14}$ LINDBECK, A.; SNOWER, D. J. Wage setting, unemployment, and insider-outsider relations. American Economic Review, n 76, 1986.

${ }^{15}$ AXELROD, R. The evolution of cooperation. Nova York: Basic Books, 1985; GRANOVETTER, M. Economic action and social structure: the problem of embeddedness. American Journal of Sociology, $n^{\circ}$ 91, 1985.

${ }^{16}$ HALL, P. A.; SOSKICE, David. An introduction to varieties of capitalism. In: HALL, P. A.; SOSKICE, D. (coord.). Varieties of capitalism: the institutional foundations of comparative advantage. New York: Oxford University Press, 2001. 
Japão). Embora os autores costumem se referir a essas variedades de capitalismo como "economias de mercado" (liberal e coordenada, respectivamente), afirma-se que a diferença entre economias liberais e coordenadas se deve a que, nas primeiras, as relações entre os agentes são mais predominantemente de mercado.

Sob certo ponto de vista, a dicotomia mercado/não mercado tem aqui um sentido igual ao anterior, no qual "mercado" designa relações sujeitas a variações de oferta e demanda. As “interações estratégicas" 17 que caracterizam as economias coordenadas, no entanto, também se contrapõem ao mercado no sentido de substituir, em parte, a competição entre os agentes e de pôr associações representativas, como associações comerciais e sindicatos, no papel de tomadoras de decisão em substituição às firmas e agentes individuais.

\subsection{Mercado como “lugar” de satisfação de preferências}

A dicotomia mercado/não mercado também pode ser entendida, por fim, à maneira do que Elster propõe ao distinguir "mercado" e "fórum". ${ }^{18}$ No sentido de Elster, o mercado é o "lugar” onde preferências são satisfeitas. 0 fórum, em contrapartida, é o lugar da deliberação, onde os agentes procuram definir normas ou cursos de ação razoáveis, isto é, que todos possam aceitar. A diferença fundamental entre o mercado e o não mercado reside, aqui, nas motivações dos agentes. Enquanto as relações de mercado se caracterizam pela disposição de satisfazer preferências, nas de não mercado (ou no “fórum”), o objetivo dos agentes é resolver problemas de racionalidade prática em termos razoáveis.

\subsection{Relações entre os diferentes sentidos da dicotomia}

Acima, distinguiram-se cinco acepções do termo "mercado": mercado como liberdade de contratar (1), como liberdade para alienação onerosa (2), como falta de contrato ou algo que se lhe equipare (3), como falta de coordenação ou “interações estratégicas" entre os agentes (4) e como lugar de satisfação de preferências (5). Fazem-se, a seguir, algumas considerações sobre

\footnotetext{
17 HALL, P. A.; SOSKICE, David. An introduction to varieties of capitalism. In: HALL, P. A.; SOSKICE, D. (coord.). Varieties of capitalism: the institutional foundations of comparative advantage. New York: Oxford University Press, 2001, p. 5.

${ }^{18}$ ELSTER, J. The market and the forum: three varieties of political theory. In: ELSTER, J.; HYLLAND, A. (coord.). Foundations of social choice theory. Cambridge: Cambridge University Press, 1986.
} 
as relações entre essas acepções. Para comodidade, serão usados os números de 1 a 5 para designar cada uma delas.

(1) e (2) são, é claro, muito próximas. A particularidade de (2) é que o mercado se define em contraposição ao que é juridicamente possível alienar gratuita, mas não onerosamente, enquanto (1) tem em vista quaisquer limites jurídicos à liberdade de contratar. (3), por sua vez, é consideravelmente distinta das duas primeiras. Em (3), o mercado pode ser substituído por uma simples decisão das partes (por exemplo, a decisão de se vincularem contratualmente por um certo tempo). Se há algum papel que o direito exerça em tal caso, é apenas o de permitir que essas relações de não mercado se instaurem, por exemplo, reconhecendo validade a contratos de execução continuada ou não reputando proibidas, porque contrárias à concorrência, cláusulas contratuais ou práticas que protejam uma relação contra variações de oferta e demanda. Pode ocorrer, no entanto, de um limite jurídico a liberdade de contratar forçar a substituição do mercado (3) pelo contrato, tal como ocorre no Brasil em relação às locações imobiliárias para fins residenciais (Lei n 8.245/1991, arts. 46 e 47).

(4) pode ser entendida como um caso especial de (3), em que a suscetibilidade a variações de oferta e demanda é diminuída por interações estratégicas que substituem a competição e decisões individuais pelas de associações representativas. Tal como em (3), os impedimentos jurídicos à liberdade de contratar não têm necessariamente um papel na substituição do mercado em (4), a não ser o de permitir que tal substituição ocorra (por exemplo, acordos entre empresários para não competir sobre preços são, frequentemente, proibidos pela legislação antitruste). Normas jurídicas podem, não obstante, favorecer a substituição do mercado pela coordenação, como no caso de normas que incentivem a formação de sindicatos ou que forcem à negociação coletiva de salários.

(5), por fim, discrepa consideravelmente das demais. Impedimentos jurídicos à liberdade de contratar podem resultar de processos de deliberação caracterizados pela busca de termos razoáveis de cooperação. Os mesmos impedimentos também podem, contudo, reagir a falhas de mercado e, como tais, simplesmente ter em vista preferências que os agentes, à falta de limites para a liberdade de contratar, não conseguiriam satisfazer. Na primeira hipótese, há uma coincidência entre o que se contrapõe ao mercado em (1), e também (2), e (5). Na segunda, não. Similarmente, em (3) e (4), o contrato e a coordenação podem constituir simples estratégias alternativas para atender às preferências dos agentes, e são, de fato, frequentemente concebidos como tais. Eles são, em tal caso, uma alternativa ao mercado nos sentidos de (3) e (4), mas sua motivação é a que caracteriza o mercado em (5). Considere os 
casos de um contrato de longa duração ou de uma negociação coletiva entre sindicatos de patrões e trabalhadores, alternativas ao mercado nos sentidos de (3) e (4), respectivamente. Em ambos os casos, podem-se imaginar as partes motivadas a perseguir apenas seus interesses, isto é, a conseguir acordos mais vantajosos possíveis para si. É só se o comportamento estratégico, assim entendido, der lugar à disposição para coordenar as ações sob termos que todos possam aceitar (inclusive terceiros cujos interesses estão em jogo) que essas instâncias de não mercado nas acepções (3) e (4) passarão a sê-lo também no sentido de (5). ${ }^{19}$

\section{VÁRIOS “MERCADOS”: ALGUM PROBLEMA?}

Em princípio, não há problema em que um termo seja usado em diferentes acepções. 0 que pode, sim, causar problema do ponto de vista metodológico é que nossas conclusões sejam viciadas por premissas que ora usem o termo em uma de suas acepções, ora em outra. Isso pode arruinar tanto argumentos normativos sobre o mercado, isto é sobre a defensabilidade (ou indefensabilidade) moral do mercado, como argumentos sobre suas consequências empíricas.

Para ilustrar o inconveniente de ignorar a diferença entre os vários "mercados", esta seção critica o argumento de Dworkin sobre o valor do mercado para uma sociedade igualitária.

\subsection{A igualdade de recursos de Dworkin e o mercado}

No liberalismo igualitário de Dworkin, ${ }^{20}$ o mercado é declarado indispensável. Em Dworkin, a igualdade ambicionada não é de bem-estar, mas de recursos. Não se pretende, pois, que todos tenham o mesmo bem-estar, mas que recursos sejam distribuídos igualmente. Isso põe a questão de como o valor de cada recurso há de ser aferido, de modo que os lotes de recursos de diferentes cidadãos possam ser comparados.

\footnotetext{
${ }^{19} \mathrm{~V}$. HUSSAIN, W. Nurturing the sense of justice: the Rawlsian argument for democratic corporatism. In: O'NEILL, M.; WILLIAMSON, T. (coord.). Property-owning democracy: Rawls and beyond. Malden: Blackwell, 2012. 0 autor defende o que chama de "corporatismo democrático", uma versão de capitalismo com considerável grau de coordenação. Diferentemente, porém, do que provavelmente ocorre nos casos reais de economias coordenadas, Hussain quer que as corporações (sindicatos, associações comerciais, etc.) incumbidas de definir as regras do jogo atuem deliberativamente ao invés de barganhar pela maior vantagem possível.

20 DWORKIN, R. Sovereign virtue: the theory and practice of equality. Cambridge: Harvard University Press, 2000.
} 
Uma intuição fundamental para o igualitarismo de Dworkin gira em torno da distinção entre o que ele chama de "sorte de opção" (option luck) e "sorte bruta" (brute luck). ${ }^{21} \mathrm{~A}$ primeira se refere às consequências de escolhas, e a segunda às de fatos involuntários. Para Dworkin, é um imperativo da igualdade que diferenças quanto à sorte bruta sejam abolidas, mas não diferenças quanto à sorte de opção.

Como a intuição acerca das sortes bruta e de opção é considerada pela igualdade de recursos? Como dito, a igualdade de recursos depende de uma definição acerca do valor de cada recurso. A maneira de fazer com que essa definição seja sensível às escolhas das pessoas (e, consequentemente, aos efeitos da sorte de opção) é, primeiro, estipular que os recursos que cabem a cada um sejam resultado de uma escolha. Recursos devem ser, em outras palavras, adquiridos voluntariamente, ao invés de simplesmente distribuídos por alguma autoridade. Segundo, é preciso que o valor de cada recurso seja definido tendo em vista as consequências da decisão de adquiri-lo. Essas consequências consistem em custos de oportunidade para outras pessoas, ${ }^{22}$ isto é, naquilo que outras pessoas "perdem" quando alguém se apropria do recurso em questão.

A igualdade de recursos depende, portanto, de instituições sob as quais a aquisição de recursos seja voluntária e a um preço condizente com os respectivos custos de oportunidade para outras pessoas. Essas instituições, segundo Dworkin, são as do mercado. Uma igual distribuição de recursos pressupõe, portanto, "an economic market of some form, mainly as an analytical device but also, to a certain extent, as an actual political institution". ${ }^{23}$

Para entender melhor o papel do mercado na igualdade de recursos dworkiniana, consideremos o famoso exemplo dos náufragos chegados a uma ilha deserta. ${ }^{24}$ Suponhamos que, para arrematar os recursos da ilha, cada náufrago disponha de 100 conchas. 0 náufrago A usa, então, a totalidade das suas conchas para arrematar o lote de recursos $x$. Sob algumas condições (entre elas, a de não haver restrições ao comércio), pode-se afirmar que nenhum dos demais náufragos está disposto a pagar pelo lote $x$ mais do que $A$, já que, se estivesse, parte ou a totalidade desse lote ficaria consigo, e não com A. Por exemplo, se ignorarmos, para simplificar, a possibilidade de divisão do lote, é uma consequência da irrestrição ao comércio (bem como de outras condições, como a inexistência de custos de transação) que nenhum outro náufrago está

${ }^{21}$ DWORKIN, R. Sovereign virtue: the theory and practice of equality. Cambridge: Harvard University Press, 2000, p. 73-74.

${ }^{22}$ Ibidem, p. 6.

${ }^{23}$ Ibidem, p. 66.

${ }^{24}$ Ibidem, p. 66 e s. 
disposto a pagar pelo lote $x$ as mesmas 100 ou mais conchas, pois, se estivesse, teria arrematado o lote ou forçado A a pagar mais por ele. A possibilidade do comércio (sob certas condições) implica, pois, que os custos de oportunidade para os demais (medidos pela disposição a pagar) não sejam superiores ao que cada um paga pelo lote que the coube. ${ }^{25}$

A respeito da defesa do mercado em Dworkin devem ser feitas duas ressalvas. Primeiro, a igualdade não será atendida se alguns cidadãos tiverem mais do que outros para despender com a aquisição de recursos e se essa diferença se dever à sorte bruta. Para que os resultados do mercado não sejam corrompidos por diferenças de sorte bruta, é preciso que o poder de compra seja igual ao início. No caso dos náufragos, a igualdade de poder de compra é assegurada mediante a entrega de um igual número de conchas para serem usadas no leilão dos recursos disponíveis na ilha. ${ }^{26}$ Em sociedades reais, por sua vez, a igualdade de poder de compra deve ser realizada por medidas redistributivas, em particular a tributação de heranças e doações de pais para filhos. $^{27}$

Segundo, mesmo que os cidadãos comecem suas vidas com igual poder de compra, os resultados do mercado ainda serão influenciados pelos efeitos da sorte bruta sobre a capacidade de cada um para auferir renda. Algumas aptidões inatas são socialmente mais apreciadas do que outras e, em consequência, dão lugar a diferenças de sorte bruta. Outros cidadãos, também devido à "loteria natural” ou a infortúnios ocorridos ao longo da vida (não relacionados a riscos assumidos), podem estar simplesmente incapacitados para o trabalho ou necessitar de uma provisão comparativamente maior de recursos para subsistir ou realizar certos "funcionamentos", como o de se locomover. Dworkin propõe tratar dessas diferenças de sorte bruta por meio de um "mercado de seguros hipotético", no qual os cidadãos estariam aptos a

\footnotetext{
${ }^{25}$ Repare, no entanto, que, se os custos de oportunidade são medidos pela disposição a pagar, é simplesmente falso que a igualdade de recursos considere que os recursos estão igualmente divididos quando "the total transferable resources of each person have the same aggregate opportunity costs". DWORKIN, R. Sovereign virtue: the theory and practice of equality. Cambridge: Harvard University Press, 2000, p. 149. Imagine dois cidadãos A e B. O lote de A tem valor de 125 conchas para A (isto é, é o número máximo de conchas que $A$ daria pelo lote em questão) e de 100 para B. O lote de $B$, por sua vez, vale 90 conchas para A e 110 para B. Supondo-se que os lotes sejam indivisíveis, as possibilidades de comércio estão esgotadas e nenhum dos cidadãos inveja o lote de recursos do outro (isto é, o teste da inveja foi satisfeito). No entanto, os custos de oportunidade para B do direito de propriedade de A sobre o seu lote são maiores do que os custos de oportunidade para A do direito análogo de B.

${ }^{26}$ DWORKIN, R. Sovereign virtue: the theory and practice of equality. Cambridge: Harvard University Press, 2000, p. 68.

27 Ibidem, p. 346-349.
} 
contratar seguro para alguns desses infortúnios. ${ }^{28} \mathrm{Em}$ sociedades reais, recursos deveriam ser redistribuídos de maneira a replicar os resultados desse mercado, com o pagamento de prêmios por todos os cidadãos (possivelmente como tributos) e de indenizações (possivelmente como transferências) aos que são vítimas dos sinistros cobertos pelo seguro hipotético.

0 argumento de Dworkin em favor do mercado não deve ser entendido, portanto, como um argumento em favor de mercados reais em relação aos quais não tenham sido tomadas medidas contra diferenças advindas de sorte bruta. Por outro lado, uma vez tomadas essas medidas, o mercado é, como visto, uma condição necessária da igualdade.

\subsection{Qual mercado? O problema da preferência pelo comércio razoável}

Podemos indagar agora qual ou quais são as acepções de mercado que Dworkin tem em vista, e se o seu argumento sobre o valor do mercado para a igualdade é congruente com elas. Quanto a isso, chama a atenção que Dworkin rejeite certos limites à liberdade de contratar ao defender o que chama de princípio da abstração. Esse princípio:

establishes a strong presumption in favor of freedom of choice. It insists that an ideal distribution is possible only when people are legally free to act as they wish except so far as constraints on their freedom are necessary to protect security of person and property, or to correct certain imperfections in markets (or other auction-like distributive mechanisms). ${ }^{29}$

Ponhamos de lado, por ora, o problema das imperfeições de mercado a que Dworkin alude no fim da passagem acima. Qual é a razão para a presunção em favor da liberdade perante a lei que o princípio da abstração institui? A resposta é que o princípio da abstração deve ser observado para que os recursos sejam distribuídos de acordo com seus custos de oportunidade verdadeiros (true opportunity costs). ${ }^{30}$ Custos de oportunidade são falseados à medida que limites a liberdade tornem as possibilidades de aquisição e uso dos recursos insensíveis às preferências das pessoas. Por exemplo, a restrição à compra de lotes de terra com área inferior à de um campo de futebol tornaria o comércio de terras insensível às preferências de pessoas que queiram lotes menores para fins diversos. Tal restrição daria lugar, pois, a preços

\footnotetext{
${ }^{28}$ DWORKIN, R. Sovereign virtue: the theory and practice of equality. Cambridge: Harvard University Press, 2000, p. 78-79.

${ }^{29}$ Ibidem, p. 148.

${ }^{30}$ Ibidem, p. 150-151.
} 
distorcidos, isto é, não condizentes com os custos de oportunidade das pessoas a cujas preferências o comércio em questão é insensível.

0 princípio da abstração é limitado de algumas maneiras. Uma delas é por um princípio de segurança. ${ }^{31}$ Certas restrições a liberdade, como a proibição à violência e ao roubo, são necessárias para que as pessoas contem com usar seus recursos do modo como ambicionam. Sem a segurança oferecida por essas restrições, portanto, os preços dos recursos comercializados ficariam insensíveis às preferências das pessoas cujo uso dos recursos em questão seja ameaçado pela intervenção alheia. Outro princípio, o da correção, permite restrições à liberdade para fazer frente a distorções de preço ocasionadas por externalidades. ${ }^{32}$ Por exemplo, uma construção nociva aos vizinhos pode ser proibida sob a alegação de que, com ela, chegaríamos a um resultado mais próximo do de circunstâncias ideais nas quais os vizinhos coordenariam suas ações (sem ter de arcar com os respectivos custos de transação) a fim de pagar o suficiente para que a obra em questão não se realizasse.

Embora a distinção entre sorte bruta e de opção ressalte a importância moral das escolhas, são as preferências, portanto, mais do que as escolhas, o que o igualitarismo de Dworkin leva em consideração. Essa conclusão é corroborada pelo recém mencionado princípio da correção, que justifica limites à liberdade a fim de nos aproximarmos dos resultados de escolhas que os cidadãos fariam, dadas as suas preferências, em circunstâncias ideais (por exemplo, com custos de transação iguais a zero). As preferências é que contam, também, para supor as escolhas que seriam feitas sobre a contratação do seguro hipotético e as políticas redistributivas que esse seguro implica.

Há vários problemas, já bem conhecidos, em juízos de moralidade política baseados em preferências. Preferências podem ser imorais ou heterônomas. ${ }^{33}$ Quanto às primeiras, Dworkin defende o princípio da independência, ${ }^{34}$ que exclui do cálculo igualitário algumas preferências "externas", ${ }^{35}$ como, por exemplo, a preferência de um racista pela segregação. Dworkin reluta, por outro lado, em aceitar, como $\operatorname{Cohen}^{36}$ propõe, que preferências sejam tratadas

${ }^{31}$ DWORKIN, R. Sovereign virtue: the theory and practice of equality. Cambridge: Harvard University Press, 2000, p. 152.

32 Ibidem, p. 155-157.

${ }^{33}$ ELSTER, J. Sour grapes: studies in the subversion of rationality. Cambridge: Cambridge University Press, 1983, p. 22.

${ }^{34}$ DWORKIN, R. Sovereign virtue: the theory and practice of equality. Cambridge: Harvard University Press, 2000, p. 161.

${ }^{35}$ DWORKIN, R. Taking rights seriously. Cambridge: Harvard University Press, 1977, p. 234-235.

${ }^{36}$ COHEN, G. A. On the currency of egalitarian justice. Ethics, $n^{\circ} 4,1989$, p. 921-924. 
diferentemente conforme tenham ou não sido deliberadamente desenvolvidas (ou conforme seja ou não possível livrar-se delas).

Postas de lado as complicações do último parágrafo, podemos nos perguntar, enfim, em qual sentido o mercado é imprescindível para o igualitarismo de Dworkin. Tendo em vista as referências tanto ao princípio da correção quanto ao seguro hipotético, pode-se concluir que o mercado é, para Dworkin (em suas próprias palavras), mais um instrumento analítico (analytical device) do que uma real instituição. A "métrica" da igualdade de recursos é a dos custos de oportunidade, os quais são aferidos não com base nas escolhas que as pessoas realmente fazem, mas que fariam, em circunstâncias ideais, tendo em vista as preferências que têm. Não seria um problema para a igualdade de recursos, aparentemente, se, ao invés de ocorrer de acordo com escolhas reais, a distribuição de recursos fosse feita por uma autoridade onisciente que lograsse entregar a cada cidadão um lote de recursos que maximizasse a satisfação das suas preferências e fosse igual aos demais lotes quanto aos custos de oportunidade. Uma autoridade que replicasse os resultados de escolhas só não seria um substituto perfeito das escolhas mesmas como meio de satisfação de preferências se e à medida que essas preferências envolvam o processo de escolha. ${ }^{37}$

Um problema é que se, para Dworkin, o mercado se parece mais com um "lugar" para a satisfação de preferências, então o princípio da abstração, que apenas resguarda a liberdade (incluindo a liberdade de contratar), é um princípio incompleto. Consideremos o caso de cidadãos que, usufruindo da liberdade assegurada pelo princípio da abstração, substituam a barganha pela deliberação (pode se tratar tanto da deliberação de fato como de um comportamento conforme ao que se supõe que seria decidido deliberativamente). Há inúmeros exemplos possíveis, como os de decisões de patrões e empregados sobre salários e demais condições de trabalho, de consumidores sobre as condições de fair trade a serem observadas pelos produtos que consumirão e de empresários e vizinhos sobre níveis de poluição. Em todos esses casos, podemos supor que os envolvidos tenham as atitudes deliberativas do "fórum" de Elster, isto é, que, ao invés de barganhar pela satisfação de suas preferências, eles procurem coordenar suas ações sob termos que todos possam aceitar.

Atos conformes aos resultados de deliberação permitidos pelo princípio da abstração afrontam a igualdade de recursos. À medida que conformem seu comportamento ao que foi deliberado, os cidadãos causarão uma distorção de preços dos recursos, os quais já não serão

\footnotetext{
${ }^{37}$ SEN, A. Maximization and the act of choice. Econometrica, ${ }^{\circ} 65,1997$.
} 
mais sensíveis apenas aos custos de oportunidade para os demais. Consumidores que decidem pagar um sobrepreço por produtos de fair trade só por entenderem que é o certo a fazer, por exemplo, pagarão pelos produtos em questão mais do que deveriam segundo a métrica dos custos de oportunidade. ${ }^{38}$

A afirmação do parágrafo anterior pressupõe que, ao decidir pagar mais por um produto de fair trade, consumidores não estejam simplesmente satisfazendo a uma preferência como qualquer outra (como uma preferência altruísta em favor das pessoas que vivem do comércio em questão). Se assim fosse, seria possível dizer que o preço pago dependeria dos custos de oportunidade de duas preferências distintas, a preferência pelo produto em si e por beneficiar outrem. Não haveria, portanto, à luz da métrica dos custos de oportunidade, distorção alguma.

Há uma razão, contudo, para que a preferência por atuar segundo termos que todos possam aceitar não seja tratada como uma preferência qualquer. Essa "preferência pelo comércio razoável”, como será chamada aqui doravante, distingue-se de outras preferências envolvidas em atos de comércio pela insuscetibilidade à derrogação. Não podemos ter uma preferência por interagir com outros em termos razoáveis sem que ela se sobreponha a preferências pelos resultados do comércio que eventualmente a contradigam. Não é coerente, por exemplo, que alguém afirme ter preferência por atuar segundo termos razoáveis a não ser que isso cause considerável dano para si. ${ }^{39}$ A segunda parte da afirmação contradiz a primeira, porque estar disposto a atuar razoavelmente é estar disposto a atuar segundo termos não necessariamente vantajosos ou até bastante desvantajosos para si, contanto, é claro, que razoáveis. $^{40}$

\footnotetext{
${ }^{38}$ Certamente não é o caso de aplicar o princípio da correção para as distorções de preço mencionadas acima. Esse princípio supre, como visto, as falhas quanto à satisfação de preferências decorrentes de externalidades. Em relação à decisão do consumidor que paga mais por um produto de fair trade, entretanto, o problema não são as externalidades (externalidades positivas são um problema quando não ocorrem). Não parece, tampouco, que uma versão ampliada do princípio da correção fosse capaz de sanar a distorção provocada por cidadãos que tomam decisões de compra à base dos resultados de deliberação. Em tal versão, o princípio da correção teria que dar lugar a medidas de compensação em favor dos cidadãos em questão, o que, além de difícil de pôr em prática, possivelmente seria recusado pelos próprios beneficiados caso percebessem a intenção por trás dessas medidas.

39 Não há incoerência, por outro lado, em ter uma preferência por atuar razoavelmente contanto que outros (todos, ou a maioria) também o façam. A preferência pelo comércio razoável pode ser condicionada. Ela não pode, contudo, ser condicionada a certos resultados do comércio, pois uma tal condição é incompatível com a preferência em questão.

${ }^{40}$ Nisso a preferência pelo comércio razoável se diferencia de uma preferência altruísta. Não é contraditório com afirmar uma preferência minha pelo seu bem-estar que eu considere essa preferência derrogável se, por exemplo, o seu bem-estar estiver em conflito com o meu.
} 
0 ponto, ressalte-se, não é que não se possa ter a preferência pelo comércio razoável e atuar em desacordo com ela, seja por desinformação ou por "fraqueza de vontade" (akrasia). Preferências estão frequentemente em conflito e, apesar de reconhecermos à preferência pelo comércio razoável uma posição hierárquica superior, podemos, ocasionalmente, ceder à tentação de uma outra preferência qualquer. 0 que não se pode é ter a preferência pelo comércio razoável como preferência subordinada a preferências por certos resultados não razoáveis, pois essa subordinação seria incongruente com a preferência que dizemos ter.

0 fato de a preferência pelo comércio razoável se diferenciar de preferências quanto aos resultados do comércio é importante para a igualdade de recursos de Dworkin pela razão exposta a seguir. Os cidadãos de Dworkin podem ser entendidos (à maneira dos náufragos chegados à ilha deserta) como portadores de preferências interna e externamente conflitantes. Preferências são internamente conflitantes no sentido de os recursos sob controle de uma mesma pessoa serem limitados, de modo que a decisão de um cidadão de satisfazer a uma preferência sua $x$ frequentemente implica a renúncia a satisfazer a uma outra preferência $y$. Preferências também são externamente conflitantes, agora no sentido de que os mesmos recursos são aptos a satisfazer às preferências de cidadãos diversos.

Como os recursos são escassos, o uso de um recurso para satisfazer a uma preferência do cidadão A diminui a probabilidade de que $B$ tenha as suas preferências satisfeitas. Tendo em vista esses dois conflitos, a igualdade de recursos é baseada em uma "divisão de trabalho" segundo a qual, por um lado, cada cidadão fica encarregado de dirimir conflitos internos, isto é, de decidir sobre quais de suas preferências serão satisfeitas com os recursos de que dispõe, e em que medida. A sociedade, por outro lado, deve se encarregar da solução dos conflitos externos, de modo a fazer com que cada cidadão, ao se apropriar de um lote de recursos, não imponha um sacrifício demasiado às preferências dos demais. A preferência pelo comércio razoável, contudo, põe em xeque esse "trabalho social". É como se alguns cidadãos, ao preterirem algumas de suas preferências em favor da preferência pelo comércio razoável, abrissem mão de disputar os recursos disponíveis em pé de igualdade com os demais. Ao realizarem sua preferência pelo comércio razoável, os cidadãos ocultam suas preferências quanto a resultados e rompem, com isso, a relação entre preços e custos de oportunidade. ${ }^{41}$

\footnotetext{
${ }^{41}$ Uma objeção é que, em uma sociedade na qual as condições da igualdade de recursos sejam atendidas, a preferência pelo comércio razoável se tornaria irrelevante para as decisões dos agentes, já que qualquer comércio ocorrido sob tais condições seria razoável. Cidadãos com a preferência pelo comércio razoável não teriam que se preocupar, portanto, com os preços que pagam pelos recursos que adquirem, uma vez
} 
Há de se observar que há uma diferença entre o problema levantado aqui e o do que trata Dworkin ao criticar o utilitarismo devido às preferências externas. ${ }^{42}$ Dworkin afirma que a pretensão do utilitarismo de dar às preferências de cada um o mesmo peso cairá por terra se, entre as preferências consideradas, estiverem preferências acerca da utilidade de outras pessoas. Uma vez que essas preferências, que Dworkin chama de "externas", entrem no cálculo utilitarista, a consequência será que a utilidade das pessoas que são objeto das preferências em questão terá um peso diferenciado, maior (caso as preferências externas sejam benévolas) ou menor (se malévolas). Ao desenvolver a sua concepção de igualdade, Dworkin não se debruça sobre o problema das preferências externas, a não ser para defender o já citado princípio da independência (Dworkin, 2000: 161) em favor de pessoas vítimas de preconceito capaz de causar "serious or pervasive disadvantage". Nenhuma menção é feita, contudo, a preferências externas benévolas ou malévolas com efeitos mais modestos. Essa omissão pode se dever ao fato de, depois de enfrentar o problema das preferências externas em outra obra, Dworkin ter considerado suficiente se referir ao caso mais grave dessas preferências ao apresentar a sua concepção de igualitarismo.

Também é possível, no entanto, que algumas preferências externas acabem reconhecidas pela igualdade de recursos porque são, afinal de contas, preferências. Se A tem preferências acerca do próprio bem-estar e do bem-estar de B, ignorar as segundas sob a alegação de evitar vantagem ou desvantagem a B não deixa de causar distorção de preços e de ser, nesse sentido, iníquo para A.

Em contrapartida, não há, paradoxalmente, nenhum sentido no qual considerar a preferência de alguns cidadãos pelo comércio razoável seja um passo em direção à igualdade. Como a preferência pelo comércio razoável não concorre, no sentido exposto acima, com as demais preferências dos cidadãos em questão sobre os resultados do comércio, a igualdade de recursos só é atendida quando tal preferência é posta de lado. Daí não segue, ressalte-se, que devam ser tomadas medidas para impedir que os cidadãos atuem segundo a preferência em questão. Pode haver várias razões para desejar que os cidadãos tenham essa preferência e se comportem de acordo com ela, razões não necessariamente relacionadas apenas aos efeitos

que a razoabilidade do comércio que praticam estaria institucionalmente assegurada. Nem todos os cidadãos necessariamente concordarão, porém, com que os termos de comércio razoáveis sejam os que decorrem da observância às condições da igualdade de recursos. Mesmo que esses cidadãos estejam errados, é suficiente que possuam a preferência em questão e que atuem com base nela para que a violação à igualdade mencionada acima se verifique.

42 DWORKIN, R. Taking rights seriously. Cambridge: Harvard University Press, 1977, p. 234-235. 
imediatos desse comportamento. ${ }^{43} 0$ que se diz aqui é apenas que o fato de alguns cidadãos realizarem a sua preferência pelo comércio justo em substituição a preferências que tenham quanto aos resultados do comércio atenta contra a igualdade tal como concebida por Dworkin.

Embora não seja necessariamente a única explicação, é possível que o problema da preferência pelo comércio razoável tenha sido ocultado por uma confusão entre dois sentidos do termo "mercado", os da ausência de impedimentos jurídicos à liberdade de contratar e o de "lugar" de satisfação de preferências. Não haveria tal problema, de fato, se os agentes do mercado, entendido como âmbito das trocas não sujeitas a impedimentos jurídicos, fossem invariavelmente agentes do mercado no sentido de atuarem invariavelmente para a satisfação das suas preferências.

\section{CONCLUSÃO}

Este artigo teve dois objetivos. O primeiro foi apresentar algumas das diferentes acepções com as quais o termo “mercado" é usado na literatura. O segundo, sugerir que a atenção para os diferentes significados do termo pode ser útil para a avaliação de argumentos normativos sobre o mercado. Esse segundo ponto foi ilustrado por uma análise do argumento de Dworkin em defesa do mercado como instituição igualitária. Demonstrou-se que a igualdade ambicionada por Dworkin não é assegurada pela mera falta de impedimentos jurídicos a liberdade de contratar, o que dá lugar a um descompasso entre os princípios defendidos por institucionais de Dworkin (em especial, o princípio da abstração) e o ideal de igualdade que ele tem em vista.

\section{REFERÊNCIAS}

AXELROD, R. The evolution of cooperation. Nova York: Basic Books, 1985.

AYRES, I. Regulating opt-out: an economic analysis of altering rules. Yale Law Journal, $\mathrm{n}^{\circ} .121$, 2012.

BEN-SHAHAR, O.; POTTOW, J. A. E. On the stickiness of default rules. Florida State University Law Review, n³3, 2006.

43 Por exemplo, pode-se chegar à conclusão de que a preferência pelo comércio razoável está positivamente correlacionada a uma preferência por instituições justas. 


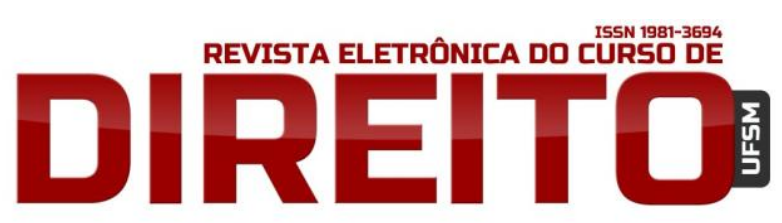

MERCADO E IGUALDADE: NOTAS SOBRE O USO DO TERMO "MERCADO" E UMA CRÍTICA A DWORKIN

LEANDRO MARTINS ZANITELLI

BERNSTEIN, L. Social norms and default rules analysis. Southern California Interdisciplinary Law Journal, n 3, 1993.

COHEN, G. A. On the currency of egalitarian justice. Ethics, n 4, 1989.

DWORKIN, R. Taking rights seriously. Cambridge: Harvard University Press, 1977.

DWORKIN, R. Sovereign virtue: the theory and practice of equality. Cambridge: Harvard University Press, 2000.

ELSTER, J. Sour grapes: studies in the subversion of rationality. Cambridge: Cambridge University Press, 1983.

ELSTER, J. The market and the forum: three varieties of political theory. In: ELSTER, J.; HYLLAND, A. (coord.). Foundations of social choice theory. Cambridge: Cambridge University Press, 1986.

GRANOVETTER, M. Economic action and social structure: the problem of embeddedness. American Journal of Sociology, $n^{\circ}$ 91, 1985.

HALL, P. A.; SOSKICE, David. An introduction to varieties of capitalism. In: HALL, P. A.; SOSKICE, D. (coord.). Varieties of capitalism: the institutional foundations of comparative advantage. New York: Oxford University Press, 2001.

HUSSAIN, W. Nurturing the sense of justice: the Rawlsian argument for democratic corporatism. In: O'NEILL, M.; WILLIAMSON, T. (coord.). Property-owning democracy: Rawls and beyond. Malden: Blackwell, 2012.

JOHNSTON, J. S. Strategic bargaining and the economic theory of contract default rules. Yale Law Journal, n 100, 1990.

KAHNEMAN, D.; KNETSCH, J. L.; THALER, R. (1986). Fairness as a constraint on profit seeking: entitlements in the market. American Economic Review, $\mathrm{n}^{\circ}$ 76, 1986.

KLEIN, B.; CRAWFORD, R. G.; ARMEN, A. A. Vertical integration, appropriable rents, and the competitive contracting process. Journal of Law and Economics, $n^{\circ} 21,1978$.

KOROBKIN, R. The status quo bias and contract default rules. Cornell Law Review, n 83, 1998.

LINDBECK, A.; SNOWER, D. J. Wage setting, unemployment, and insider-outsider relations. American Economic Review, n 76, 1986.

MILLER, D. Market, state and community: theoretical foundations of market socialism. Oxford: Clarendon Press, 1989.

RABIN, M. Incorporating fairness into game theory and economics. American Economic Review, $\mathrm{n}^{\circ} .83,1993$. 
SATZ, D. Why some things should not be for sale: the moral limits of markets. Oxford: Oxford University Press, 2010.

SEN, A. Maximization and the act of choice. Econometrica, $n^{\circ}$ 65, 1997.

SPIER, K. E. Incomplete contracts and signalling. RAND Journal of Economics, $n^{\circ} 23,1992$.

TOMASI, J. Free market fairness. Princeton: Princeton University Press, 2012.

WILLIAMSON, O. E. The mechanisms of governance. Nova York: Oxford University Press, 1996.Axelrod, R. (1985): “The evolution of cooperation”. Basic Books, New York. 